Proceedings

\title{
Above Ground Live and Dead Biomass Distribution Using Allometric Equation in the Restored Mines of the PPC's Western Macedonia Lignite Center ${ }^{+}$
}

\author{
Gavriil Spyroglou 1,*, Mariangela Fotelli ${ }^{1}$, Nikos Nanos ${ }^{2}$ and Kalliopi Radoglou ${ }^{3}$ \\ ${ }^{1}$ Forest Research Institute, Hellenic Agricultural Organization DEMETER, Thessaloniki, Greece; \\ spyroglou@fri.gr; fotelli@fri.gr \\ ${ }^{2}$ Department of forestry and natural environment, Aristotle University of Thessaloniki, University \\ Campus 54124 Greece ; nikosnanos@for.auth.gr \\ ${ }^{3}$ Department of Forestry and Management of Environment and Natural Resources, Democritus \\ University of Thrace, Pandazidou 193 str. 68200 N. Orestiada, Greece.; kradoglo@fmenr.duth.gr \\ * Correspondence: spyroglou@fri.gr \\ + Presented at the 6th International Electronic Conference on Sensors and Applications, 15-30 \\ November 2019; Available online: https://ecsa-6.sciforum.net/
}

Published: 2020

\begin{abstract}
Forests and forest plantations are ranked first in storing carbon and play a substantial role in climate change mitigation. The assimilated carbon is stored in the above and below ground parts of the trees; in dead wood; in litter and in soil. The Greek power generation and supply company, PPC S.A. started environmental rehabilitation projects to rehabilitate the restored areas after the end of the exploitation at the open cast lignite mines of the Lignite Center of Western Macedonia in the 80s by planting different tree species; mainly black locust. Today some of these plantations are almost forty years old and occupy 2,200 ha in total. The dominant planted species is the black locust (Robinia pseudoacacia L.), a fast-growing pioneer species; covering $95 \%$ of the planted area. Other planted species are Spartium junceum; and Cupresus arizonica; covering $2.45 \%$ and $1.44 \%$, respectively. The aim of this study was to measure and estimate the live and dead above ground biomass distribution across the planted sites of the restored waste dumps of Amyntaio and Ptolemaida lignite mines. 215 sample plots of $100 \mathrm{~m}^{2}$ each were set up through systematic sampling in a grid dimension of $500 \times 500 \mathrm{~m}$. In each sample plot the tree species; $\mathrm{dbh}(\mathrm{cm})$, tree height and the height to live crown $(\mathrm{m})$ were recorded for all trees. The above ground biomass was estimated using an exponential allometric model. The results have shown that in the tree planted restored areas of Amyntaio mine the above ground biomass ranges from 20.1 to $90.2 \mathrm{tn} \mathrm{ha} \mathrm{H}^{-1}$ and in that of the Ptolemaida mine from 11.6 to $75.8 \mathrm{tn} \mathrm{ha}^{-1}$. The spatial biomass distribution seems to show a trend to increase from Southeast to Northwest in Ptolemaida and from West to North in the Amyntaio mine. The standing dead wood ranged from 0 to 19.8 tn ha ${ }^{-1}$ for Amyntaio; and 0 to 41.9 for Ptolemaida mine respectively; and for the lying dead wood 0.5 to 19.5; and 0.5 to $66 \mathrm{~m}^{3} \mathrm{ha}^{-1}$. The overall decay degree in the quality scale from 1 to 5 was ranged as: $10 \%$ for $1 ; 27 \%$ for $2 ; 45 \%$ for $3 ; 17 \%$ for 4 and $1 \%$ for 5 . The black locust shows a remarkable ability to survive and grow on disturbed sites such as the restored mines of the Lignite Center of Western Macedonia. It is very competitive compared to other planted species and has created the necessary forest environment for the natural regeneration of other; more shade tolerant and soil demanding species such as oaks and maples
\end{abstract}


Keywords: climate change mitigation; forest restoration; forest biomass estimation; standing and lying dead wood; variogram model; kriging regression

\section{Introduction}

Forests and forest plantations are ranked first in storing carbon and play a substantial role in climate change mitigation [1]. The assimilated carbon is stored in the above and below ground parts of the trees, in dead wood, in litter and in soil. The estimation of the quantity of forest biomass is important to assess forest growth and productivity [2]. It is also necessary in estimating carbon stored in a forest or plantation because carbon comprises about half of the dry biomass $[2 ; 3]$. The role of forests on the carbon sequestration and on carbon cycle generally is important [3].

Open-cast coal mines have a great negative impact on the landscape degradation [4]. Moreover, one of the major environmental concerns regarding the open-cast coal mining areas is the generation of dust through blasts, transportation onto large tracks or conveyors and processing activities, which have severe impact on the air quality. In European countries more than $50 \%$ of the mined lands are reclaimed as forest or grass lands [4].

The Greek power generation and supply company, PPC S.A. started environmental rehabilitation projects to rehabilitate the restored areas after the end of the exploitation at the open cast lignite mines of the Lignite Center of Western Macedonia in the 80s by planting different tree species, mainly black locust (Robinia pseudoacacia L.). Today, this is still an ongoing process and some of these plantations on the final surfaces of the waste dumps are almost forty years old occupying more than 2,200 ha in total. The dominant planted species is the black locust, a fast-growing pioneer species, covering $95 \%$ of the planted area followed by weaver's broom (Spartium junceum L) and Arizona cypress (Cupresus arizonica Greene), covering $2.45 \%$ and $1.44 \%$, respectively. Other planted species comprise oaks, maples, pines and various deciduous broadleaves in very small percentages. Black locust is a species native to North America and has been introduced in Europe at the beginning of the 17th century [5]. In Greece, this species has been mainly introduced and planted for torrents stabilization in the mountains and for soil erosion control on rivers, road and railway banks because of its dense root system. It has been also used as an alternative crop of private-owned plantations for its fast growing capabilities and good adaptation to marginal agricultural lands [6]. Black locust, despite the expressed concerns for its invasiveness $[7,8]$ it is a species with special capabilities, apart from its fast growing ability, it is considered as undemanding species [9]. It can tolerate alkalic soils with $\mathrm{pH}$ up to 8 [10], as a legume species has the ability of nitrogen fixation [11]. It can tolerate drought and survive on poor soils with less nutrients supply like the former open-cast mining areas [12]. The aim of this study was to measure and estimate the live and dead above ground biomass distribution across the planted sites of the restored waste dumps of Amyntaio and Ptolemaida lignite mines.

\section{Methods}

The data used in the present study were collected from the restored former open-cast mining areas of the lignite center of Western Macedonia. The plantations are located near the Amyntaio city within geographic coordinates of 40.56 to $40.61 \mathrm{~N}$ and 21.62 to $21.69 \mathrm{E}$ and near Ptolemaida city within geographic coordinates of 40.39 to $40.51 \mathrm{~N}$ and 21.7 to $21.89 \mathrm{E}$. The total size of the planted area is approximately $22,000 \mathrm{ha}$. For the estimation of the distribution of the above ground biomass totally 215 sample plots of $100 \mathrm{~m}^{2}$ each were set up through systematic sampling in a grid dimension of $500 \times 500 \mathrm{~m}$ in the restored former open-cast mining areas of Amyntaio and Ptolemaida. In each sample plot the tree species, diameter at breast height $(d b h)$ in $\mathrm{cm}$, tree height $(\mathrm{Ht})$ and the height to live crown $(\mathrm{Hlc})$ in $\mathrm{m}$ were recorded for all trees. The lying dead wood was recorded for all trees or pieces of trees that were lying within the surface of the plot, the measured variables were the diameter at the two ends of the tree or $\log$ in $\mathrm{cm}$, the length in $\mathrm{m}$ and the decay degree in scale 1 to 5 [13]. The above ground biomass was estimated using an exponential allometric model of the form 
$\mathrm{M}=\mathrm{a} * \mathrm{dbhb}$. For the calibration of the allometric equation, 30 black locust trees covering all diameter range were destructively sampled during the summers of 2019 and 2020. The diameter at stump height $(\mathrm{D} 0.3 \mathrm{in} \mathrm{cm})$ and at breast height $(\mathrm{D} 1.3 \mathrm{in} \mathrm{cm})$ was measured before the tree felling. The sampled trees were cut at the stump height $(0.30 \mathrm{~m})$, and, after felling, total tree height $(\mathrm{H}$ in $\mathrm{m})$, diameter at $50 \%$ of bole length (D0.5 in $\mathrm{cm}$ ) and diameter at the base of live crown were recorded. Each one of the 30 stems was divided into six sections (including the stump) after felling, and fresh biomass of each stem section was measured in the field. From each section, a stem disk $7 \mathrm{~cm}$ wide was removed, weighed, taken to the laboratory, and oven dried at $80^{\circ} \mathrm{C}$ until a constant weight was reached to determine the fresh/oven-dried biomass ratio. The fresh biomass of the whole crown was also weighed in the field and taken to the laboratory and oven dried at $80^{\circ} \mathrm{C}$ until a constant weight was reached [14].

For the estimation of the spatial distribution of the aboveground biomass a geostatistical approach was applied. The spatial analysis was conducted in R programing language [15] using gstat library for variogram analysis and modeling. The parameters of the best variogram model (nugget, range and partial sill) were used in ordinary kriging interpolation [16].

\section{Results and Discussion}

The black locust stands show high heterogeneity with dbh ranging from 1.4 to $22.3 \mathrm{~cm}$ and the biomass per hectare ranging from 0.6 to 256.6 ton ha- ${ }^{-1}$. More specifically, in the tree planted restored areas of Amyntaio mine the above ground biomass ranges from 20.1 to 90.2 tn ha- $^{-1}$ and in the tree planted restored areas of Ptolemaida mine ranges from 11,6 to 75,8 th ha $^{-1}$. The Spherical, Gaussian and exponential variogram models that fitted in the dataset are those that usually applied in the ecological studies [17]. The semi-variograms of above ground biomass in both sites effectively described by the spherical model, changes of the spatial distribution of above ground biomass are affected by both structural and random factors. The magnitude of the spatial correlation of above ground biomass is considered medium with Nugget to total Sill ratio being between $25 \% \sim 75 \%$. Besides structural factors' effect, effect of random factors such as sampling grid resolution, plot size and precision of the allometric equation on the biomass estimation also play an important role to the relatively high nugget effects recorded. The spatial biomass distribution seems to show a trend to increase from Southeast to Northwest in Ptolemaida and from West to North in the Amyntaio mine showing the spatial direction of the planting process in the past years. The standing dead wood ranged from 0.37 to 19.8 tn ha- $^{-1}$ for Amyntaio, and 0.06 to 41.9 for Ptolemaida mine respectively, and for the lying dead wood 0.5 to 19.5 , and 0.5 to $66 \mathrm{~m}^{3}$ ha-1. The overall decay degree in the quality scale from 1 to 5 was ranged as: $10 \%$ for $1,27 \%$ for $2,45 \%$ for 3 , $17 \%$ for 4 and $1 \%$ for $5.83 \%$ of the dead wood concentrates in decay degrees 1,2 and 3 denoting an increase in competition and self-thinning of the trees in the last 10 years considering that these plantations have not been thinned before.

\section{Conclusions}

- The spatial distribution of the above-ground biomass of black locust of Lignite center of Western Macedonia was effectively estimated using ordinary kriging approach.

- The total above ground biomass estimated by ordinary kriging was 138,778 tons for Amyntaio and 44,052 for Ptolemaida mining areas and 182,830 tons in total.

- The dead standing and lying wood represents $5-7 \%$ of the standing wood mass and it is expected to increase if the forest created from these plantations remain out of management in the future.

- The black locust (Robinia pseudoacacia L.), due to its nitrogen fixing and stress tolerant characteristics, shows a remarkable ability to survive and grow on disturbed sites such as the restored land of open cast lignite mines of the Lignite Center of Western Macedonia. It is fast growing and thus very competitive compared to other planted species forming stands with full canopy closure and consequently, has created the necessary forest environment for the natural regeneration of other, more shade tolerant and soil demanding species such as oaks and maples. 
Author Contributions: conceptualization, G.S. and N.N.; methodology, G.S. and N.N.; software, G.S and N.N.; validation, M.F., N.N.; formal analysis, G.S. and N.N.; investigation, G.S.; data curation, G.S and N.N.; writing - original draft preparation, G.S; writing-review and editing, G.S; M.F.; supervision, K.R.; project administration, K.R.; funding acquisition, K.R.

Funding: This research was funded by Single RTDI state Aid Action Research -Create -Innovation with the co- financial of Greece and the European Union (European Regional Development Fund) in context with Operational Program Competitiveness, Entrepreneurship and Innovation (ЕПАNEK) of the NSRF 2014-2020 (project Contribution of the tree planted land of West Macedonia lignite center to protection of environment and to mitigation of climate change T1EDK-02521).

Acknowledgments: The authors would like to acknowledge the Hellenic PPC S.A. for the provision of assisting personnel and necessary infrastructure during field campaigns and data collection. Special thanks are due to Lamprini Patmanidou and Simela Andreadi along with Marina Tentsoglidou, Aris Azas, Christos Papadopoulos and their teams.

Conflicts of Interest: The authors declare no conflict of interest.

\section{References}

1. Nabuurs, G.J., O. Masera, K. Andrasko, P. Benitez-Ponce, R. Boer, M. Dutschke, E. Elsiddig, J. FordRobertson, P. Frumhoff, T., Karjalainen, O. Krankina, W.A. Kurz, M. Matsumoto, W. Oyhantcabal, N.H. Ravindranath, M.J. Sanz Sanchez, X. Zhang, 2007: Forestry. In Climate Change 2007: Mitigation. Contribution of Working Group III to the Fourth Assessment Report of the Intergovernmental Panel on Climate Change [B. Metz, O.R. Davidson, P.R. Bosch, R. Dave, L.A. Meyer (eds)], Cambridge University Press, Cambridge, United Kingdom and New York, NY, USA.

2. Brown, S. Estimating biomass and biomass change of tropical forests: A primer. FAO Forestry Paper 1997,134. UNFAO, Rome, Italy. 55 p.

3. Pan, Y., R.A. Birdsey, J. Fang, R. Houghton, P.E. Kauppi, W.A. Kurz, O.L. Phillips, A. Shvidenko, S.L.Lewis, J.G. Canadell, P. Ciais, R.B. Jackson, S.W. Pacala, A.D. McGuire, S. Piao, A. Rautiainen, S. Sitch, and D. Hayes. A large and persistent carbon sink in the world's forests Science 2011, 333, 988-993.

4. Usuga, J.C.L., J.A.R. Toro, M.V.R. Alzate, A.J.L. Tapias. Estimation of biomass and carbon stocks in plants, soil and forest floor in different tropical forests. Forest Ecology and Management 2010, 260 (10), 1906-1913.

5. Peabody, Fr.J. A 350-Year-Old American Legume in Paris. Castanea 47, no. 1 1982, 99-104. Accessed November 6, 2020. http://www.jstor.org/stable/4033219.

6. Dini-Papanastasi, O., Panetsos, C.P. Relation between growth and morphological traits and genetic parameters of Robinia pseudoacacia var. monophylla DC in northern Greece. Silvae genetica 2000, 49, 37-44.

7. Dini-Papanastasi, O., Arianoutsou, M., Papanastasis, V.P. Robinia pseudoacacia L.: a dangerous invasive alien or a useful multi-purpose tree species in the Mediterranean environment? , Ecology, Conservation and Management of Mediterranean Climate Ecosystems. CD of Proceedings of 10th MEDECOS Conference, April 25-May 1 2004, Rhodes, Greece, 2004 Rotterdam, The Netherlands Millpress

8. Richardson, D.M.; Rejm?nek, M. Trees and shrubs as invasive alien species-A global review. Divers. Distrib.2011, 17, 788-809.

9. Carl, C.; Biber, P.; Landgraf, D.; Buras, A.; Pretzsch, H. Allometric Models to Predict Aboveground Woody Biomass of Black Locust (Robinia pseudoacacia L.) in Short Rotation Coppice in Previous Mining and Agricultural Areas in Germany. Forests 2017, 8, 328. doi:10.3390/f8090328

10. Gomez, T.;Wagner, M. Culture and use of black locust. Hort Technol. 2001, 11, 279-288.

11. Moshki, A., Lamersdorf, N.P. Symbiotic nitrogen fixation in black locust (Robinia pseudoacacia L.) seedlings from four seed sources. Journal of Forestry Research 2011, 22, 689 doi: 10.1007/s11676-011-0212-6 
12. Mantovani, D.; Veste, M.; B?hm, C.; Vignudelli, M.; Freese, D. Spatial and temporal variation of drought impact on black locust (Robinia pseudoacacia L.) water status and growth. iForest 2015, 8, 743. doi: 10.3832/ifor1299-008

13. Daskalakou, E., Karetsos, G., Tsagari, C., Vassilopoulos,G., Baloutsos G. Preliminary results of deadwood estimation, as a biodiversity indicator in four representative forest ecosystems of Greece. Forest Research (Dassiki Erevna) 2008, 21, 19-28. In Greek with English abstract.

14. Zianis, D., Spyroglou, G., Tiakas, E., Radoglou k.m. Bayesian and classical models to predict aboveground tree biomass allometry 2016, Forest Science 62 (3), 247-259

15. R Core Team. R: A language and environment for statistical computing. R Foundation for Statistical Computing, 2014 Vienna, Austria. Available online: URL http://www.Rproject.org (accessed on 6 September 2020).

16. Ribeiro, P.J., Jr., and P.J. Diggle. geoR: A package for geostatistical analysis. R-NEWS 2001, 1, 15-18.

17. Fortin, M.J., Dale, M.R.T. Spatial analysis: A guide for ecologists. 2005. Cambridge, UK, Cambridge University Press. 365 p.

Publisher's Note: MDPI stays neutral with regard to jurisdictional claims in published maps and institutional affiliations.

(C) 2020 by the authors. Submitted for possible open access publication under the terms and conditions of the Creative Commons Attribution (CC BY) license (http://creativecommons.org/licenses/by/4.0/). 